\title{
Pericardial Synovial Sarcoma
}

National Cancer Institute

\section{Source}

National Cancer Institute. Pericardial Synovial Sarcoma. NCI Thesaurus. Code C147102.

A rare synovial sarcoma that arises from the pericardium. Patients present with symptoms related to pericardial effusion. 